\title{
Exchange rate regimes and macroeconomic instabilities in Sub-Saharan Africa
}

\author{
Camara Seydou Yaya ${ }^{4}$
}

\begin{abstract}
This article addresses macroeconomic instabilities according to exchange rate regimes in Sub-Saharan Africa (SSA). Based on International Monetary Fund's exchange rate regimes de facto classification, the global sample, SSA, is first divided into two subsamples, which are countries within CFA franc zone (ZCFA) and those outside CFA franc zone (HZCFA), and then into four categories, which are the Western Economic and Monetary Union (WAEMU), the Central African Economic and Monetary Community, the countries CFA franc zone with fix exchange rate regimes(HZCFA-FIX), and the countries outside CFA franc zone with flexible exchange rate regimes(HZCFA-FLEX). By applying advanced statistical and econometric methods upon internal and external macroeconomic equilibrium conditions, we show that the inflation, the GDP (or the output) and the real exchange rate (RER) are very volatile in SSA. However, we found out that they are more volatile in the group HZCFA comparatively to the group ZCFA. We also found out that they are higher in the group HZCFA-FIX than the group HZCFA-FLEX. Moreover, we found out that a high instability of the inflation is combined with those of the output and the RER.
\end{abstract}

KEY WORDS: policy objectives, stabilization policy, econometrics, semi-parametric and non-parametric methods, statistical simulations

JEL: E610, E630, B23, C14, C15

UDC: $338.246(292.63 / .69)$

$330.101 .514: 330.43$

339.743

COBISS.SR-ID 219513612

${ }^{4}$ Corresponding author, GREDEG-CNRS, University of Nice Sophia Antipolis, e-mail: yscamara@gmail.com 


\section{Introduction}

Herein we carry out an empirical and comparative study of macroeconomic instabilities according to exchange rate regimes in Sub-Saharan Africa (SSA). The macroeconomic instabilities are a major and general topic in economic analysis because of their effects. Indeed, they affect all sectors of an economy with consequences more or less harmful for populations and business environment. However, this issue becomes even more important when dealing with developing countries for the simple reason that developing countries often may not have possibilities to carry out countercyclical economic policies when those are necessary. Especially, Sub-Saharan African countries are poor countries that heavily depend on international aid and revenues from the trade of their commodities on international markets of commodities. Therefore, these economies need a more stable and viable economic environment necessary for investment, consumption and trade. But despite the fact that this topic is very important in economic analysis, one of the important issue of this major topic is the measurement of a macroeconomic instability itself.

Generally, the general tendency consists of computing either the standard deviation or computing the difference between the variable under consideration and another variable or standard. Therefore, these measurements give only a descriptive explanation at a specific time, whereas it would rather be more interesting to understand the dynamic of a macroeconomic instability over time in order to make assumptions and conclusions for the medium and long terms. This approach is especially important of since the macroeconomic stability is assumed as one of the most important factors for promoting the economic growth in developing countries, and particularly in SSA. Thus, recommendations of economic policies should be shaped in accordance with countries' macroeconomic instabilities and their exchange rate regimes. This is really important and even fundamental in decision making of economic policies. Unfortunately, studies focus often to show an empirical relationship between macroeconomic instabilities and economic growth, and as a consequence they treat less macroeconomic instabilities themselves. Hence, our main contribution in this article will consist of treating macroeconomic instabilities' dynamics in SSA with respect to underlying exchange rate regimes.

The theoretical framework of this study considers a general macroeconomic equilibrium that requires that the internal equilibrium and the external equilibrium must be realized simultaneously. Based on this approach, the stability of prices and the fluctuations of the gross domestic production, the GDP or simply the output, reflect the internal equilibrium indicators (stability of internal macroeconomic policy), while the gaps between the RER and the equilibrium real exchange rate (ERER) reflect the external equilibrium stability indicator (stability of external macroeconomic policy). The internal equilibrium means or at least requires that the instability of prices and output gaps must be very low and very stable. And then, the external equilibrium requires that the current account, or generally the balance of payments, must be in equilibrium over medium and long terms without being harmful for the economic growth at all. Indeed, the RER must not undergo important and persistent deviations over medium term or long term.

The basic hypothesis behind the assumptions above is that macroeconomic variables standing for internal equilibrium and external equilibrium conditions are related each other over time. Thus, our approach will consist of using statistical and econometric methods that allow to model conditional variances of each variable with taking into account those of other variables at the same time. Therefore, we aim to estimate co-volatilities of inflation 
gaps, output gaps and RER gaps over time. In order to achieve this goal, we will use multivariate GARCH (MGARCH) methods at the first step. But recalling that MGARCH techniques require a very deep time dimension, which is not the case here as our time dimension is not long enough, we will use non parametric techniques that keep correlation structure between variables in the case where our parametric methods fail. Indeed, we will complete our approach by semi-parametric and non-parametric methods and especially by using simulation techniques (Monte Carlo) of correlated variables and density estimates.

The rest of the article is organized into five sections. In the first section, we present a literature review of macroeconomic instabilities and MGARCH models. In the second section, we will introduce the econometric models, especially CCC (Constant Conditional Correlations) and DCC (Dynamic Conditional Correlations) GARCH models that we will be using in the parametric estimates. In the third section we will introduce the global sample and the subsamples, and the data and its treatment. The fourth section will present the estimates' procedures, while we will present results and commentary in the fifth section. And then the article will be ended up by a conclusion.

\section{Review of literature}

The macroeconomic instabilities in developing countries have become a major topic that preoccupies experts and institutions working on economic development issues because they directly or indirectly affect the social wellness, and because of the fact that the fluctuations of the output are harmful for the consumption, the production and the employment. Thus, the study of Bleaney (1996) on macroeconomic instabilities and growth in developing countries is one of the most forerunner contributions of this thematic for developing countries. Indeed, selecting a number of indicators of macroeconomic instability (or stability) such as the fiscal deficit, the volatility of RER, the public debt and the inflation over the period 1980-1990, the author shown negative correlations between the fiscal deficit and the economic growth, and between the instability of the RER and the economic growth. As results, the author concluded that the macroeconomic stability is combined with a high level of economic growth for a given level of investment. However, recent empirical studies on economic growth in developing countries take into account many other factors such as institutions, culture and geography, etc. in addition to macroeconomic instabilities Acemouglu (2009).

The studies of Aizenman \& Pinto (2005) and Wolf (2005) pointed out some transmission mechanisms of the macroeconomic instabilities. According to the authors, negative effects of macroeconomic instabilities can appear through economic, political and social uncertainties, which cause economic costs for a given economy. According to Guillaumont (2006), Aizenman \& Pinto (2005), Agénor (2001) and Aguiar \& Gopinath (2007), the costs of macroeconomic instabilities affect factors such as the consumption, the poverty and the income inequality. And according to Hnatkovska \& Loayza (2003), countries with high macroeconomic volatility experience low economic growth that in turn affects directly or indirectly the poverty, the inequality and the human capital accumulation. For Athanasoulis \& Van Wincoop (2000), it is possible to increase the social wellness by mitigating the consumption volatility. Many other empirical studies, as those of (Ramey \& Ramey, 1995), (Fatàs, 2002), Acemouglou \& others (2003), Hnatkovska \& Loayza (2005), and Sadni-Jallab, Gbakou \& Sandretto (2008), demonstrate an evidence of negative impacts of the macroeconomic instabilities on the economic growth. These studies argue that 
developing countries in the most of the time do not have the necessary capability to face up unforeseen difficult economic situations, or simply they are unable to set up countercyclical fiscal policies when required.

One of the numerous causes of the weakness of the economic growth in SSA is the lack of necessary capital for investment. But nowadays, this issue could be obviously figured out by foreign direct investment (FDI) flows in somehow. However, the intensification of FDI flows and their role on the economic growth in recipient countries have compelled economists to look into this factor in developing countries. The study of Sadni-Jallab, Gbakou \& Sandretto (2008) questioned the impacts of the FDI in the case of North Africa and Middle East countries (MENA) for a total number of eleven countries. The results of this study led to the conclusion that the FDI flows contribute positively to economic growth only if the level of inflation is low and stable over time. And in a recent work of Abdelmalk \& al (2012), the authors questioned whether the macroeconomic stability determines the impact of the FDI flows on the economic growth and the process of emerging or not. Using a global sample formed by countries of Africa, Latin America, Caribbean and Asia chosen over the period 1990-2005, the empirical results of this study show that the FDI flows affected positively the economic growth in these countries. On the other hand, the study shows that the macroeconomic instabilities, and particularly that of inflation has a negative effect on the economic growth and limits, therefore, the impact of the FDI flows on the economic growth for the subsample of African countries. In addition, the study shows that there is a threshold effect of inflation that authors is identified to be about $112 \%$.

But as we noticed above, estimating the volatility may be very challenging, and often one estimates it by the standard deviation or by the difference between two variable. However, the ARCH (p) models, introduced by Engle (1982), and their generalized version, the GARCH (p, q) models introduced by (Bollerslev, 1986), have facilitated volatility modeling and forecasting. We recall that the letters $\mathrm{p}$ and $\mathrm{q}$ stand respectively for the numbers of lags for autoregressive (AR) and moving average (MA) parts. Even though many univariate GARCH models have been developed and are very useful for volatility estimating and forecasting, hence, the volatility of a variable may depend on those of another or other variables, and this is often the case for a macroeconomic time series. Therefore, univariate GARCH $(\mathrm{p}, \mathrm{q})$ models are not appropriate for estimating conditional correlations between a variable and others. However, multivariate GARCH models (MGARCH) have been conceived to fulfill this weakness of GARCH (p, q) models. Indeed, the MGARCH models are useful for modeling conditional correlations and conditional covolatilities between variables that are correlated other over time. The first version of MGARCH models was introduced by extension of the ARCH (p) model to two variables, which is the first version of $\operatorname{VEC}(p, q)$ model.

Indeed, the article of Engle, Granger, \& Kraft (1984) provided an approach of ARCH (p) models with two variables and in which the conditional variance of each variable depends on its own previous volatilities and those of the other variable. And then, the article of (Bollerslev, Engle, \& Wooldridge, 1984) extended this version to a GARCH (1, 1) model, which turned out as a generalized version of the $\operatorname{VEC}(1,1)$ model. However, the VEC model requires a very high number of parameters to be estimated. Therefore, a new model with $\mathrm{k}$ variables and known as $\operatorname{BEKK}(\mathrm{p}, \mathrm{q}, \mathrm{k})$ model has been introduced by Baba, Engle, Kraft \& Kroner (1990). The BEKK (p, q, k) model, with the acronym representing the initials of the authors' names who developed the so called model, allowed considerably the shrinking of the number of parameters to be estimated. For instance, in a $\operatorname{VEC}(1,1,2)$ the number of parameters is 21 , while it is only 11 for a $\operatorname{BEKK}(1,1,2)$. 
Though the BEKK model is an important contribution, the reality is that the number of parameters to be estimate is still very high. For instance, the number is equal to 164 for a BEKK model with one lag only for both AR and MA parts and eight variables, BEKK (1, $1,8)$. Thus, Bollerslev introduced the CCC model, which reduces the number of parameters to be estimated because of its hypothesis of constant conditional correlations. For a CCC ( 1 , $1,2)$ and a CCC $(1,1,3)$, the number of parameters to be estimated are 7 and 15 respectively. However, the strength of the CCC model, that is the hypothesis of constant conditional correlations, is also its weakness. Indeed, the hypothesis may be roughly reasonable for a short period, but it is unlikely reasonable for a period relatively long. In the case of financials time series, studies as those of (Sheedy, 1998) and Tse \& Tsui (2002) show that the hypothesis of constant conditional correlations is not often verified. Thus this hypothesis has been abandoned in favor of dynamic conditional correlations which resulted in introduction of DCC models by Tse, \& Tsui (2002) and Engle (2002). A literature review of the DCC models is provided in Engle \& Sheppard (2001), but the article of Bowens, Laurent, \& Rembouts (2006) is an excellent literature review of MGARCH models.

Now, our next step will introduce the univariate and multi variate GARCH models in order to explore our econometric method. Note that this step will focus on the CCC and DCC GARCH models of since our goal is to estimate conditional correlations and covolatilities.

\section{Econometric models}

Our econometric approach herein will consist of combining macroeconomic variables that reflect internal and external equilibrium conditions in order to determine their covolatilities. The choice for the CCC model is motivated by its simplicity, while the choice for DCC model relies on the fact that the goals of macroeconomic policies may change over time, and that is even more obvious for SSA in the measure that the macroeconomic policy changes are quite frequent and very rough in developing countries due to political instabilities and the nature of the economic management (often goals are neither elucidated and enumerated nor quantified).

Now, let us start by a univariate $\operatorname{GARCH}(1,1)$ model:

$$
\begin{aligned}
& y_{t}=\mu+\varepsilon_{t}, \\
& \varepsilon_{t}=z_{t} \sqrt{h_{t}}, \\
& h_{t}=\gamma+\alpha \varepsilon_{t-1}^{2}+\beta h_{t-1} \\
& \gamma, \alpha, \beta \geq 0
\end{aligned}
$$

Where, $z$ is a set of independently and identically distributed (i i d) numbers, and $\gamma, \alpha, \beta$ and $\mu$ are parameters such the sum of $\alpha$ and $\beta$ is less or equal to one $(\alpha+\beta \leq 1)$. The parameters can be estimated by the maximum of likelihood method. The equations (eq1) and (eq2) show that the variable $y_{t}$ has a conditional mean $\mu$ that is constant overtime and a conditional variance $h_{t}$ that varies over time according to the dynamic described in equation the (eq3). The CCC model proposed by Bollerslev (1990) is given as follow:

$$
y_{i, t}=\mu_{i}+\varepsilon_{i, t},
$$




$$
\left\{\begin{array}{l}
H_{t}=D_{t} R_{t} D_{t} \\
D_{t}=\text { diagonal }\left(h_{11 t, 1 / 2}^{1 / 2}, h_{N N t}^{1 / 2}\right) \\
R_{t}=\rho_{i j t}, \text { avec } \rho_{i i t}=1
\end{array}\right.
$$

Where, $R_{t}$ is $N-b y-N$ matrix of conditional correlations, and $h_{i i t}$ are given by a GARCH model, especially by the equation (eq6) below:

$$
\begin{aligned}
& h_{i i, t}=\gamma_{i}+\alpha_{i} \varepsilon_{i, t-1}^{2}+\beta_{i} h_{i i, t-1}, \\
& \gamma_{i,} \alpha_{i,} \beta_{i} \geq 0, \quad i=1,2 \ldots, N \\
& h_{i j, t}=\rho_{i j} \sqrt{h_{i i, t} h_{j j, t}} \quad \forall i \neq j
\end{aligned}
$$

The constraint of positivity of the matrix $H_{t}$ implies the positivity of the matrix $R_{t}$ and elements $h_{i i t}$, and we have:

$$
\begin{aligned}
& \boldsymbol{R}_{\boldsymbol{t}}=\boldsymbol{R}=\left(\boldsymbol{\rho}_{i j}\right), \quad \text { with } \boldsymbol{\rho}_{i i}=\mathbf{1} \\
& z_{i, t}=\frac{y_{i t}-\hat{y}_{i t}}{\sqrt{\hat{h}_{i i, t}}} \\
& \hat{\rho}_{i j}=\frac{1}{T} \sum_{\hat{i}=1}^{T} z_{i t} z_{j, t} \\
& \hat{h}_{i j, t}=\hat{\rho}_{i j} \sqrt{\hat{h}_{i i, t} \hat{h}_{j j, t}}
\end{aligned}
$$

The parameters to be estimated are $\mu_{i}$, the conditional means which are supposed linear, and the parameters $\gamma_{i}, \alpha_{i}, \beta_{i}$ and $\rho_{i j}$ (the matrix of constant conditional correlations). The equation (eq4) shows that the conditional mean of each variable $i$ is $\mu_{i}$, and the equation (eq6) shows how each co-volatility varies over time. The model can be computed in two stages, and the first will consist of computing a $\operatorname{GARCH}(1,1)$ while the second will consist of computing the matrix of conditional correlations from the errors $\left(\varepsilon_{i, t}\right)$ of the GARCH model. Note that $\hat{\rho}_{i j}$ is not the matrix of conditional correlations, but that of feasible and consistent estimators of the matrix $\rho_{i j}$. Nevertheless, before we turn to DCC models, we would like to say that we will only show those of Tse \& Tsui (2002) and (Engle, 2002). The former version is noted by $\mathrm{DCC}_{\mathrm{T}}$ and the latter is noted by $\mathrm{DCC}_{\mathrm{E}}$. The DCCT version is given as follow:

$$
\begin{aligned}
& H_{t}=D_{t} R_{t} D_{t}(e q 12) \\
& \left\{\begin{array}{l}
R_{t}=\left(1-\theta_{1}-\theta_{2}\right) R+\theta_{1} \Psi_{t-1}+\theta_{2} R_{t-1} \\
\Psi_{i j, t-1}=\frac{\sum_{m=1}^{M} u_{i, t-m} u_{j, t-m}}{\sqrt{\left(\sum_{m=1}^{M} u_{i, t-m}^{2}\right)\left(\sum_{m=1}^{M} u_{j, t-m}^{2}\right)}} \\
u_{i, t}=\frac{\varepsilon_{i t}}{\sqrt{h_{i i, t}}}
\end{array}\right.
\end{aligned}
$$


Where, $\theta_{1}, \theta_{2}>0$ and $\theta_{1}+\theta_{2}<1$, and $R$ has the same meaning as in the CCC model. The matrix $\Psi_{t-1}$ is $N-b y-N$ matrix of correlations of $\varepsilon_{\tau}$, for $\tau=t-M, t-$ $m+1, \ldots, t-1$. The necessary condition to guarantee the positivity is such as $M>N \times$ $R_{t}$, that is a weighted matrix of correlations $\left(R, \Psi_{t-1}, R_{t-1}\right)$. This matrix is positive if each element is positive. If $\theta_{1}=\theta_{2}=0$ (weighting parameters are null), we obtain the CCC model, and the matrix $\Psi_{t-1}$ is given by:

$$
\psi_{t-1}=B_{t-1}^{-1} L_{t-1} L_{t-1}^{\prime} B_{t-1}^{-1}
$$

Where, $B_{t-1}$ is a diagonal matrix with $N-b y-N$ size, and its $i^{t h}$ elements are given by $\left(\sum_{h=1}^{M} u_{i, t-h}^{2}\right)^{1 / 2}$. And, $L_{t-1}=\left(u_{t-1}, \ldots, u_{t-M}\right)$ is a matrix of $N-b y-M$ size, with $u_{t}=$ $\left(u_{1 t}, u_{2 t}, \ldots u_{N t}\right)^{\prime}$. Alternatively to the model DCCT, the DCCE is given as follow:

$$
R_{t}\left(\operatorname{diag} Q_{t}\right)^{-1 / 2} Q_{t}\left(\operatorname{diag} Q_{t}\right)^{-1 / 2}
$$

Where, $Q_{t}=\left(q_{i j, t}\right)$ is also a matrix of $N-b y-N$ size, and it is symmetric and positive. The matrix $Q_{t}$ is given by the equation (eq16):

$$
Q_{t}=\left(1-\theta_{1}^{\prime}-\theta_{2}^{\prime}\right) \bar{Q}_{t}+\theta_{1}^{\prime} u_{t-1} u_{t-1}^{\prime}+\theta_{2}^{\prime} Q_{t-1}
$$

The matrix $u_{t}$ is defined as in the DCCT model. And $\theta_{1}^{\prime}$ and $\theta_{2}^{\prime}$ are positive parameters, with $\theta_{1}^{\prime}+\theta_{2}^{\prime}<1$. If, $\theta_{1}^{\prime}=\theta_{2}^{\prime}=1$, we obtain the CCC model. The matrix $\bar{Q}$ is a matrix of conditional variances of $u_{t}$ with the size $N-b y-N$. In order to better see the difference between the two versions, we give the equations of conditional correlations for each version. The equations (eq17) and (eq18) represent the conditional correlations for the $\mathrm{DCC}_{\mathrm{T}}$ model and $\mathrm{DCC}_{\mathrm{E}}$ model, respectively.

$$
\rho_{12 t}=\left(1-\theta_{1}-\theta_{2}\right) \rho_{12}+\theta_{2} \rho_{12, t-1}+\theta_{1} \frac{\sum_{m=1}^{M} u_{1, t-m} u_{2, t} m}{\sqrt{\left(\sum_{m=1}^{M} u_{1, t-m}^{2}\right)\left(\sum_{m=1}^{M} u_{2, t-m}^{2}\right)}}
$$

$$
=\frac{\rho_{12 t}}{\sqrt{\left(\left(1-\theta_{1}^{\prime}-\theta_{2}^{\prime}\right) \bar{q}_{11}+\theta_{1}^{\prime} u_{1, t-1}^{2}+\theta_{2}^{\prime} q_{11, t-1}\right)\left(\left(1-\theta_{1}^{\prime}-\theta_{2}^{\prime}\right) \bar{q}_{22}+\theta_{1}^{\prime} u_{2, t-1}^{2}+\theta_{2}^{\prime} q_{22, t-1}\right)}}
$$

Contrarily to the $\mathrm{DCC}_{\mathrm{T}}$ model, the $\mathrm{DCC}_{\mathrm{E}}$ model does not take the conditional correlations as a weighted average of preview correlations. However, the matrix $Q_{t}$ is given by a GARCH model. As we have presented our parametric methods, we are now going in turn to introduce data and subsamples

\section{Data}

The data is collected from the World Development Indicators database known as WDI, and the time period is from 1980 to 2008 including all Sub-Saharan countries. With individual observations, we have computed average observations by subsamples according to the exchange rate regimes and by year for each variable. The global sample, SSA countries, is splitted into several subsamples or groups based on the de facto exchange rate regimes classification of the International Monetary Fund (IMF). The subsamples are as follow: 
The monetary union group, which is represented by CFA franc countries or zone (ZCFA). ZCFA itself is constituted by two subsamples, which are the West African Economic and Monetary Union (WAEMU) and the Central African Economic and Monetary Community (CAEMC). The French denominations for these to subsamples are respectively UEMOA and CEMAC. The two latter denominations are those we adopted to use afterwards

The group of fix exchange rate regimes (HZCFA-FIX), which represents the countries with fixed exchange rate accept the countries in Monetary Union (WAEMU and CAEMC). This subsample is constituted by the countries with either currency board system or conventional pegged exchange rate regimes.

The group of intermediate exchange rate regimes, which represents the countries with stabilized arrangement regime, crawling peg regime, crawl-like arrangement and pegged exchange rate within horizontal bands. Exceptionally, we do not have this subsample because these regimes were seldom chosen by SSA countries during 1980-2010.

The group of flexible exchange rate regimes (HZCFA-FLEX), which represents the countries with other managed arrangement and floating exchange rate regimes.

In our approach, we have a global sample, which is SSA, and then this is first splitted into two subsamples, which are the countries within the CFA franc zone (ZCFA) and those outside the CFA franc zone (HZCFA). And then the former is, ZCFA, is splitted into two subsamples which are WAEMU (or UEMOA in French) and CAEMC (or CEMAC in French). As the former, the latter, HZCFA, is as well splitted into two subsamples, which are the subsamples HZCFA-FIX and HZCFA-FLEX. As the countries often change their exchange regime over time, the number of countries in the subsamples HZCF-FIX and subsample HZCFA-FLEX varies over time. The evolution of exchange rate regimes' choices in SSA is exhibited in table 1 below:

Table 1: Evolution of exchange rate regimes in ASS

\begin{tabular}{||l|l|l|l|l|l|l|l||}
\hline $\mathrm{N}^{\circ}$ & Exchange Rate Regimes & 1980 & 1985 & 1990 & 1995 & 2000 & 2006 \\
\hline 1 & Monetary Union & 12 & $13^{5}$ & 13 & 13 & $14^{6}$ & 14 \\
\hline 2 & Currency Board & 0 & 0 & 0 & 0 & 0 & 0 \\
\hline 3 & Other conventional peg & 30 & 25 & 23 & 11 & 8 & 9 \\
\hline 4 & Pegged Exchange rate within horizontal bands & 0 & 0 & 0 & 0 & 0 & 1 \\
\hline 5 & Stabilized arrangement &.. &.. &.. &.. &.. &.. \\
\hline 6 & Crawling Peg & 0 & 0 & 0 & 0 & 0 & 0 \\
\hline 7 & Crawl-like arrangement & 0 & 0 & 0 & 0 & 0 & 0 \\
\hline 8 & Other managed Arrangement & 0 & 4 & 4 & 12 & 6 & 17 \\
\hline 9 & Floating rate & 0 & 2 & 5 & 11 & 19 & 6 \\
\hline \multirow{5}{*}{ Monetary Union (ZCFA) } & 12 & 13 & 13 & 13 & 14 & 14 \\
\cline { 2 - 9 } & Fixed exchange rate regimes (HZCFA-FIX) & 30 & 25 & 23 & 11 & 8 & 9 \\
\cline { 2 - 9 } & Intermediate Exchange Rate Regimes & 0 & 0 & 0 & 0 & 0 & 1 \\
\cline { 2 - 9 } & $\begin{array}{l}\text { Flexible exchange rate Regimes (HZCFA- } \\
\text { FLEX) }\end{array}$ & 0 & 6 & 9 & 23 & 25 & 23 \\
\hline & Total & 42 & 44 & 45 & 47 & 47 & 47 \\
\hline
\end{tabular}

\footnotetext{
${ }^{5}$ The number of countries passed from 12 to 13 in CFA franc with the membership of Equatorial Guinea in CAEMC

${ }^{6}$ The number of countries passed from 13 to 14 in CFA franc zone with the membership of Guinea Bissau in WAEMU zone
} 
This table is conceived by the author using de facto Classification of IMF

With regards to our variables, we point out that we have selected three indicators of macroeconomic instabilities. The indicators are the inflation gaps $(E I)$, the output gaps $(O G)$ and the RER gaps $(E Q)$. The two first reflect the internal macroeconomic equilibrium conditions, and the latter one reflects the external macroeconomic equilibrium conditions. These three variables are computed as the difference between the current level of each indicator and its long term value. Thus, we used the filter HP of Hodrick \& Prescott (1997) in order to identify long term time series for each indicator. However, we first applied log transformation to both output, note by $Y_{t}$ and RER, noted by $Q_{t}$. Therefore, the variable $y_{t}$ stands for the logarithmic transformation of $Y_{t}$ and the variable $q_{t}$ stands for the logarithmic transformation of $Q_{t}$. Unit root tests such as ADF (Dickey \& Fuller, 1981) and PP (Phillips $\&$ Perron, 1988) show that all variables are stationary and these results are not surprising since the variables have been differenced with their long-run time series respectively. The descriptive statistics and graphs are respectively shown in table 2 and table 3 below.

Table 2: Descriptive statistics

\begin{tabular}{|c|c|c|c|c|c|c|c|c|c|c|c|c|}
\hline \multirow[t]{2}{*}{ Samples } & \multicolumn{4}{|c|}{$\begin{array}{c}\text { Inflation gaps : EI } \\
\left(\pi_{t}-\bar{\pi}_{t}\right)\end{array}$} & \multicolumn{4}{|c|}{$\begin{array}{c}\text { Output gaps : OG } \\
\left(y_{t}-\bar{y}_{t}\right)\end{array}$} & \multicolumn{4}{|c|}{$\begin{array}{l}\text { RER gaps : EQ } \\
\qquad q_{t}-\bar{q}_{t}\end{array}$} \\
\hline & $\mathrm{M}$ & sd & $\min$ & $\max$ & $\mathrm{m}$ & sd & $\min$ & $\operatorname{Max}$ & $\mathrm{m}$ & $\mathrm{sd}$ & $\min$ & $\max$ \\
\hline SSA & $-1.0347 \mathrm{e}-07$ & 146 & -158 & 545 & -0.0005 & 0.02 & -0.03 & 0.05 & -0.02 & 0.14 & -0.26 & 0.38 \\
\hline ZCFA & $-0.034486 e-07$ & 6.1 & $\begin{array}{l}-7 \\
\end{array}$ & 27 & -0.0005 & 0.02 & -0.06 & 0.04 & $\begin{array}{l}-0.01 \\
\end{array}$ & 0.13 & -0.25 & 0.23 \\
\hline HZCFA & $-1.0342 \mathrm{e}-07$ & 218 & -235 & 815 & -0.0006 & 0.03 & -0.04 & 0.05 & -0.04 & 0.23 & -0.62 & 0.52 \\
\hline UEMOA & $-0.034474 \mathrm{e}-07$ & 5.8 & -6 & 25 & -0.002 & 0.02 & -0.05 & 0.03 & -0.01 & 0.13 & -0.25 & 0.25 \\
\hline CEMAC & $-0.034481 \mathrm{e}-07$ & 6.9 & -8 & 29.6 & -0.0002 & 0.04 & -0.12 & 0.14 & -0.01 & 0.12 & -0.25 & 0.23 \\
\hline HZCFA-FIX & $3.4482 \mathrm{e}-07$ & 499 & -868 & 2305 & -0.0600 & 0.30 & -0.77 & 0.48 & -0.15 & 0.63 & -1.18 & 1.15 \\
\hline HZCFA-FLEX & .. & 303 & -221 & 1423 & -0.0087 & 0.09 & -0.21 & 0.21 & 0.03 & 0.25 & -0.55 & 0.42 \\
\hline
\end{tabular}

The time series $\bar{\pi}_{t}, \bar{y}_{t}$ and $\bar{q}_{t}$ stand for the long-run time series obtained by the filter HP. And $\mathrm{m}$, sd, min and max stand respectively for mean, stand deviation, minimum and maximum

Table 3: Graphics of EI, OG and EQ by sub-sample

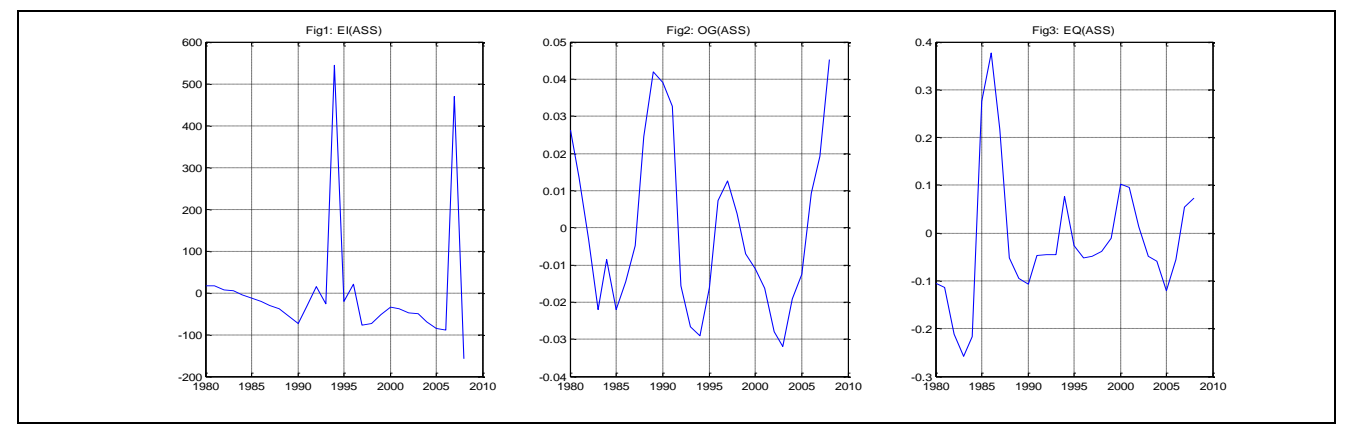



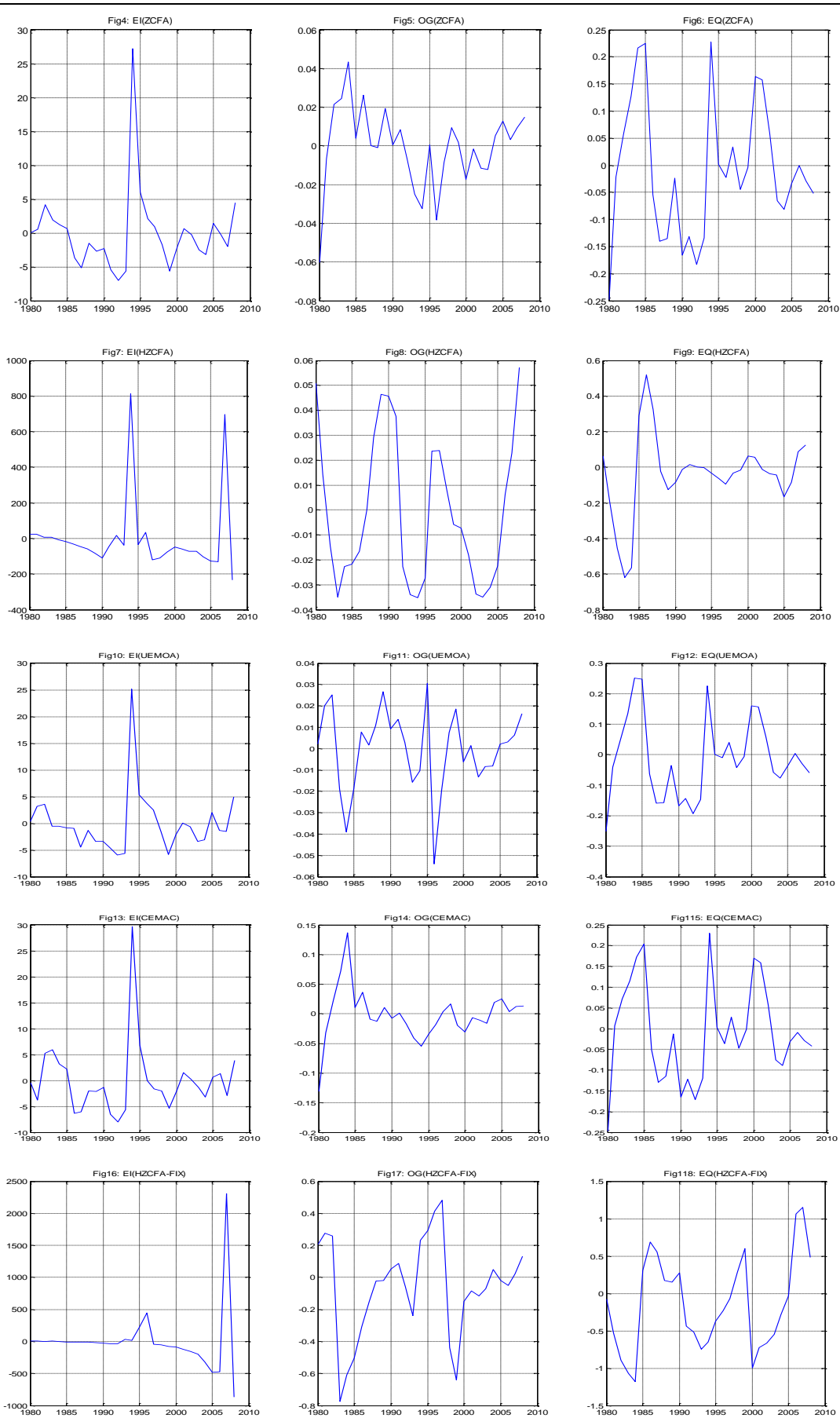


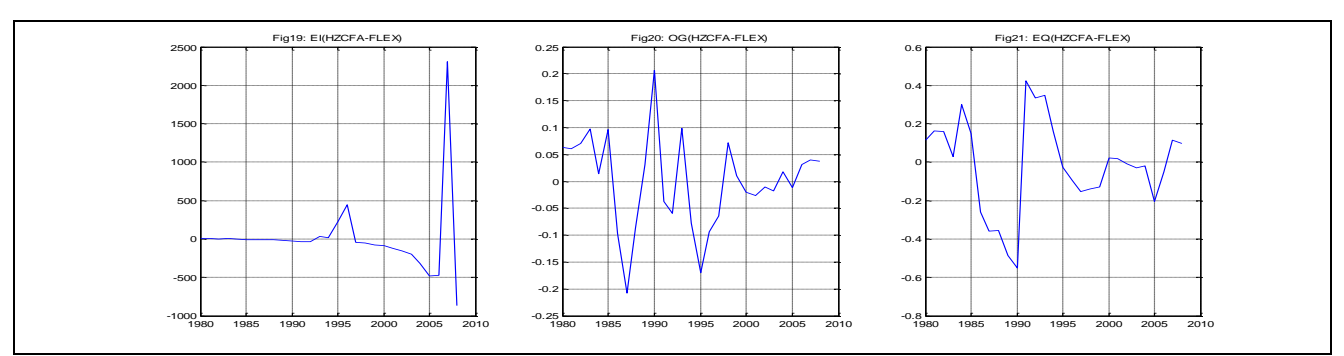

\section{Estimates}

In estimate stage, we first estimated a $\operatorname{CCC}(1,1,3)$ model for each subsample, and the results are exhibited in table 4 below. In this table, the parameters $\mu_{1}, \mu_{2}$ and $\mu_{3}$ stand for the conditional means of the variables $E I_{t}, O G_{t}$ and $E Q_{t}$, respectively. The parameters $\gamma_{1}$, $\gamma_{2}$ and $\gamma_{3}$ stand for the constant for the current conditional co-volatilities of the variables $E I_{t}, O G_{t}$ and $E Q_{t}$, respectively. The parameters $\alpha_{1}, \alpha_{2}$ and $a_{3}$ are the coefficients of $\varepsilon_{t-t}^{2}$ for $E I_{t}, O G_{t}$ and $E Q_{t}$, respectively. The parameters $\beta_{1}, \beta_{2}$ and $\beta_{3}$ are the coefficient of $h_{t-1}$ (lagged current conditional co-volatility) for $E I_{t}, O G_{t}$ and $E Q_{t}$, respectively. The parameters $\rho_{2,1}, \rho_{3,1}$ and $\rho_{2,3}$ are the constant conditional correlations between $O G_{t}$ and $E I_{t}$ $\left(O G_{t}, E I_{t}\right), E Q_{t}$ and $E I_{t}\left(E Q_{t}, E I_{t}\right), O G_{t}$ and $E Q_{t}\left(O G_{t}, E Q_{t}\right)$, respectively.

Table 4: CCC $(1,1,3)$ estimates by sub-sample

\begin{tabular}{|c|c|c|c|c|c|c|c|}
\hline Paramètres & ASS & $\mathrm{ZF}$ & HZF & UEMOA & CEMAC & HZF-FIXE & HZF-FLEX \\
\hline$\mu_{1}(E I)$ & $\begin{array}{l}-21.49144 \\
(-21.5)^{* * *}\end{array}$ & $\begin{array}{l}0.25251 \\
(0.07)\end{array}$ & $\begin{array}{l}-32.10855 \\
(-17) * * *\end{array}$ & $\begin{array}{l}0.48813 \\
(2.44)^{* *}\end{array}$ & $\begin{array}{l}0.38747 \\
(0.41)\end{array}$ & $\begin{array}{l}-21.180225 \\
(.) * *\end{array}$ & $\begin{array}{l}10.22861 \\
(0.28)\end{array}$ \\
\hline$\mu_{2}(O G)$ & -0.001664 & -0.00699 & -0.01012 & 0.00742 & -0.00363 & -0.086320 & -0.03816 \\
\hline & $(-0.64)$ & $(-391)^{* * *}$ & () & $(146) * * *$ & $(-4.48) * * *$ & $(.)^{* * *}$ & $(-114) * * *$ \\
\hline$\mu_{3}(E Q)$ & -0.044627 & -0.02220 & -0.03096 & -0.0335 & 0.00347 & -0.519764 & -0.05187 \\
\hline & $(-1.90)^{*}$ & $(-0.70)$ & $(-1.45)$ & $(-60)^{* * *}$ & $(31.45)^{* * *}$ & $(.)^{* * *}$ & $(-0.83)$ \\
\hline$\gamma_{1}(E I)$ & $\begin{array}{l}9618.161 \\
(129)^{* * *}\end{array}$ & $\begin{array}{l}15.1786 \\
(0.07)\end{array}$ & $\begin{array}{l}12703.62 \\
(149)^{* * * *}\end{array}$ & $\begin{array}{l}8.08127 \\
(5)^{* * *}\end{array}$ & $\begin{array}{l}53.57113 \\
(3.47)^{* * *}\end{array}$ & $\begin{array}{l}15.718664 \\
(.) * *\end{array}$ & $\begin{array}{l}64902.6 \\
(2.28)^{* *}\end{array}$ \\
\hline$\gamma_{2}(O G)$ & 0.000357 & 0.00049 & 0.00055 & 0.00021 & 0.00001 & 0.010060 & 0.00742 \\
\hline & $(9.73)^{* * *}$ & $(102.3)^{* * *}$ & $(107)^{* * *}$ & $(100)^{* * *}$ & $(0.58)$ & $(.)^{* * *}$ & $(42.4)^{* * *}$ \\
\hline$\gamma_{3}(E Q)$ & 0.002961 & 0.01783 & 0.00267 & 0.01851 & 0.00752 & 0.239690 & 0.00723 \\
\hline$\alpha_{1}\left(\varepsilon_{t-1}^{2}\right)$ & $\begin{array}{l}(1.29) \\
-0.075932\end{array}$ & $\begin{array}{l}(1.50) \\
0.36558\end{array}$ & $\begin{array}{l}(2.45)^{* *} \\
-0.09577\end{array}$ & $\begin{array}{l}(5.13)^{* * *} \\
1.05442\end{array}$ & $\begin{array}{l}(41.1)^{* * * *} \\
0.04723\end{array}$ & $\begin{array}{l}(.)^{* * *} \\
3.674768\end{array}$ & $\begin{array}{l}(0.38) \\
-0.00953\end{array}$ \\
\hline & $(-853)^{* * *}$ & $(0.45)$ & $(-210)^{* * *}$ & $(15)^{* * *}$ & $(1.32)$ & $(.)^{* * *}$ & $(-0.11)$ \\
\hline$\alpha_{2}\left(\varepsilon_{t-1}^{2}\right)$ & 0.886650 & $\begin{array}{l}-0.18515 \\
(-9951)^{* * *}\end{array}$ & $\begin{array}{l}0.71772 \\
(148) * * *\end{array}$ & $\begin{array}{l}0.97237 \\
(107)^{* * *}\end{array}$ & $\begin{array}{l}2.13892 \\
(9.6) * * * *\end{array}$ & 0.918084 & $\begin{array}{l}-0.13931 \\
(-454) * * *\end{array}$ \\
\hline$\alpha_{3}\left(\varepsilon_{t-1}^{2}\right)$ & 1.264026 & 0.40492 & 1.12510 & 0.40808 & -0.23319 & 0.923471 & 0.49604 \\
\hline & $(5.16)^{* * *}$ & $(1.86)^{*}$ & $(3.52)^{* * *}$ & $(5.2)^{* * *}$ & $(-308) * * *$ & $(.)^{* * *}$ & $(5.55)^{* * *}$ \\
\hline$\beta_{1}\left(h_{t-1}\right)$ & 0.606471 & 0.11546 & 0.81993 & 0.01421 & -0.34332 & 0.039924 & 0.33784 \\
\hline & $(107)^{* * *}$ & $(0.10)$ & $(2159) * * *$ & $(0.19)$ & $(-3.02)^{* * *}$ & $(.)^{* * *}$ & $(1.31)$ \\
\hline$\beta_{2}\left(h_{t-1}\right)$ & -0.329400 & 0.07661 & -0.328661 & -0.24244 & 0.00776 & -0.047593 & 0.12132 \\
\hline & $\begin{array}{l}(-1.69)^{*} \\
-0.013430\end{array}$ & $\begin{array}{l}(38.99)^{* * * *} \\
-0.48799\end{array}$ & $\begin{array}{l}(-159)^{* * * *} \\
0.05320\end{array}$ & $\begin{array}{l}(-62)^{* * *} \\
-0.36674\end{array}$ & $\begin{array}{l}(1.02) \\
0.59346\end{array}$ & $\begin{array}{l}(.)^{* * *} \\
-0.392054\end{array}$ & $\begin{array}{l}(92.7)^{* * * *} \\
0.27296\end{array}$ \\
\hline$\beta_{3}\left(h_{t-1}\right)$ & $\begin{array}{l}-0.013430 \\
(-0.33)\end{array}$ & $\begin{array}{l}-0.48 / 59 \\
(-0.51)\end{array}$ & $\begin{array}{l}0.0520 \\
(1.62)\end{array}$ & $\begin{array}{l}-0.366 / 4 \\
(-3.8)^{* * *}\end{array}$ & $\begin{array}{l}0.59346 \\
(29.1)^{* * * *}\end{array}$ & $\begin{array}{l}-0.392054 \\
(.)^{* * *}\end{array}$ & $\begin{array}{l}(0.50) \\
0\end{array}$ \\
\hline$\rho_{21}(O G, E I)$ & -0.110928 & -0.23065 & -0.068712 & 0.023183 & -0.05391 & 0.106445 & -0.23291 \\
\hline & $(-0.83)$ & $(-0.46)$ & $(-0.92)$ & $(0.17)$ & $(-0.44)$ & $(.)^{* * *}$ & $(-2.59) * * *$ \\
\hline$\rho_{31}(E Q, E I)$ & $\begin{array}{l}0.465865 \\
(3.63)^{* * *}\end{array}$ & $\begin{array}{l}0.56508 \\
(0.24)\end{array}$ & $\begin{array}{l}0.20302 \\
(3.93) * * *\end{array}$ & $\begin{array}{l}0.38622 \\
(3.44)^{* * *}\end{array}$ & $\begin{array}{l}0.58113 \\
(8.58)^{* * * *}\end{array}$ & $\begin{array}{l}-0.057671 \\
(.)^{* * *}\end{array}$ & $\begin{array}{l}0.26266 \\
(1.63)\end{array}$ \\
\hline$\rho_{32}(E Q, O G)$ & $\begin{array}{l}-0.201740 \\
(-1.13)\end{array}$ & $\begin{array}{l}0.37866 \\
(5.49) * * *\end{array}$ & $\begin{array}{l}0.09251 \\
(0.80)\end{array}$ & $\begin{array}{l}-0.25224 \\
(-4.8) * * *\end{array}$ & $\begin{array}{l}0.23989 \\
(1.74)^{*}\end{array}$ & $\begin{array}{l}0.252750 \\
(1 * *\end{array}$ & $\begin{array}{l}0.14941 \\
(0.71)\end{array}$ \\
\hline $\mathrm{N}$ & 29 & 29 & 29 & 29 & 29 & 29 & 26 \\
\hline
\end{tabular}

We remind that each estimate has three residual time series that we stored in the matrix noted $R E S_{t, i}$. In this matrix the vector $R E S_{t, 1}$ stand for the residual time series of the 
variable $E I_{t}$, the vector $R E S_{t, 2}$ stands for the residual time series of the variable $O G_{t}$ and the vector $R E S_{t, 3}$ stands for the residual time series of the variable $E Q_{t}$. Each residual time series must not be auto-correlated. However, we observed that the constraint of positivity of the parameters is not respected for any sub-sample, whereas it must be necessarily verified. Therefore, we gave up the hypothesis of constant conditional correlations in favor of the hypothesis of dynamic conditional correlations. Thus, we estimated the DCC $(1,1,3)$ model by subsample exhibited the results in table 5 below.

Table 5: DCC estimates by sub-sample

\begin{tabular}{|c|c|c|c|c|c|c|c|}
\hline Paramètres & ASS & ZF & $\mathrm{HZF}$ & UEMOA & CEMAC & HZF-FIXE & HZF-FLEX \\
\hline$\mu_{1}$ & -0.61974 & 0.59830 & 5.53387 & -74.7357 & 0.45420 & -74.7357 & -0.13692 \\
\hline & $(-0.70)$ & $(0.38)$ & $(0.07)$ & $(-0.41)$ & $(0.27)$ & $(-0.41)$ & $(-0.04)$ \\
\hline$\mu_{2}$ & 0.00101 & -0.00302 & 0.00514 & -0.0543 & -0.00482 & -0.0543 & -0.01133 \\
\hline & $(0.20)$ & $(-0.67)$ & $(0.62)$ & $(-0.51)$ & $(-0.46)$ & $(-0.51)$ & $(-0.17)$ \\
\hline$\mu_{3}$ & -0.01263 & -0.01465 & -0.02627 & -0.1082 & -0.00683 & -0.1082 & -0.01751 \\
\hline & $(-0.29)$ & $(-0.39)$ & $(-0.31)$ & $(-0.85)$ & $(-0.30)$ & $(-0.85)$ & $(-0.08)$ \\
\hline$\gamma_{1}$ & 17452.8 & 31.20026 & 37759.45 & 221323.4 & 34.82944 & 221323.4 & 44.85139 \\
\hline & $(18.02) * * *$ & $(1.60)$ & $(3.81)^{* * *}$ & $(5.34)^{* * *}$ & $(5.91)^{* * *}$ & $(5.33)^{* * *}$ & $(0.96)$ \\
\hline$\gamma_{2}$ & 0.00029 & 0.00034 & 0.00045 & 0.0472 & 0.00090 & 0.0472 & 0.00498 \\
\hline & (1.31) & (3.74) & $(93)^{* * *}$ & (1.01) & $(1.01)$ & (1.01) & $(1.21)$ \\
\hline$\gamma_{3}$ & 0.00610 & 0.01022 & 0.00958 & 0.2239 & 0.01003 & 0.2239 & 0.02994 \\
\hline 13 & $(0.73)$ & $(7.93)^{* * *}$ & $(1.94)^{* *}$ & $(3.23) * * *$ & $(2.59)^{* * *}$ & $(3.22)^{* * *}$ & (1.03) \\
\hline$\alpha_{1}$ & -0.09313 & 0.04380 & -0.07826 & 0.1183 & -0.01172 & 0.1183 & -0.03608 \\
\hline & $(-37.9)^{* * *}$ & $(0.26)$ & $(-2.01)^{* *}$ & (1.02) & $(-1.85)^{*}$ & (1.02) & $(-0.14)$ \\
\hline$\alpha_{2}$ & 0.10818 & -0.07241 & 0.25650 & 0.1541 & 0.16433 & 0.1541 & -0.10783 \\
\hline & $(0.38)$ & $(-0.66)$ & $(0.66)$ & $(0.86)$ & $(0.56)$ & $(0.86)$ & $(-0.51)$ \\
\hline$\alpha_{3}$ & 0.22165 & 0.03911 & 0.24563 & 0.1352 & -0.04141 & 0.1352 & 0.15016 \\
\hline & (1.00) & $(0.22)$ & $(1.41)$ & $(3.24)^{* * *}$ & $(-0.20)$ & $(3.24)^{* * *}$ & $(6.23)^{* * *}$ \\
\hline$\beta_{1}$ & 0.38024 & 0.38251 & 0.35957 & 0.4125 & 0.34253 & 0.4125 & 0.40471 \\
\hline & $(49.08)^{* * *}$ & $(1.76)^{*}$ & $(3.08)^{* * * *}$ & $(4.53)^{* * *}$ & $(2.97)^{* * *}$ & $(4.53)^{* * *}$ & (1.02) \\
\hline$\beta_{2}$ & 0.18437 & 0.19674 & 0.02099 & 0.1775 & 0.20317 & 0.1775 & 0.26201 \\
\hline & $(0.67)$ & $(0.96)$ & $(0.07)$ & $(0.79)$ & $(1.31)$ & $(0.79)$ & $(0.49)$ \\
\hline$\beta_{3}$ & 0.17717 & 0.26574300 & 0.06252 & 0.2105 & 0.32008 & 0.2105 & 0.21269 \\
\hline & $(0.80)$ & $\begin{array}{l}(0.90) \\
\end{array}$ & $(0.36)$ & (1.17) & $(2.04)^{* *}$ & (1.17) & $\begin{array}{l}(0.41) \\
0.20933\end{array}$ \\
\hline$\theta_{1}$ & $\begin{array}{l}0.00000 \\
(1.00)\end{array}$ & $\begin{array}{l}0.12260725 \\
(0.90)\end{array}$ & $\begin{array}{l}0.00000 \\
(8.11)^{* * * *}\end{array}$ & $\begin{array}{l}0.1478 \\
(2.03)^{* * *}\end{array}$ & $\begin{array}{l}0.05777 \\
(0.53)\end{array}$ & $\begin{array}{l}0.1478 \\
(2.03)^{* * *}\end{array}$ & $\begin{array}{l}0.20933 \\
(0.56)\end{array}$ \\
\hline$\theta_{2}$ & 0.60414 & 0.00000000 & 0.13973 & 0.0000 & 0.00000 & 0.0000 & 0.00000 \\
\hline & $(0.43)$ & $(0.73)$ & $(0.10)$ & $(0.00)$ & $(0.00)$ & $(0.00)$ & $(0.00)$ \\
\hline $\mathrm{N}$ & 29 & 29 & 29 & 29 & 29 & 29 & 26 \\
\hline
\end{tabular}

The parameters $\mu_{1}, \mu_{2}, \mu_{3}, \gamma_{2}, \gamma_{3}, \alpha_{1}, \alpha_{2}, a_{3}, \beta_{1}, \beta_{2}, \beta_{3}$ have the same meanings as in the CCC model (table 4). The parameters $\theta_{1}$ and $\theta_{2}$ represent the weights defined in the DCC model. The dynamic conditional correlations, noted $\rho_{i, j, t}$, can be extracted from the correlations matrix. In table 5, we however observe that most parameters have been improved and have become positive for each subsample. But, the positivity constraint is still not respected for all parameters, except the estimate for the subsample UEMOA (WAEMU). Therefore, we must make estimates with constraints on parameters if we want to remediate to this difficulty. But as we use the maximum of likelihood estimate method, using constraints on parameters may cause convergence problems during iteration process because of the fact our time dimension is not deep enough. Another difficulty is related to the residual time series autocorrelations. In fact, whenever we face to autocorrelation problems, the easiest way to correct that will imply introduction of one or several lags of each variable in the model. However, we will not be able to do that of since our time dimension is not long enough. For example, if we introduce one lag in the model, the number of variables will rise from 3 to 6 . Thus, the number of parameters to be estimated becomes greater than the number of observations. For these technical reasons, we are 
forced to give up the DCC model too. Nevertheless, we can opt for flexible methods, especially semi-parametric and non-parametric methods.

We recall that we would have kept exploring parametric methods if we had time series with a very long time dimension. However, as we ae obliged to use flexible methods, we first simulated correlated variables using Monte Carlo simulations, and then we performed kernel estimate in the second stage. These procedures are justified because we still take into account our basic hypothesis that considers that macroeconomic policies management relies on macroeconomic gaols that are linked with one another. Although parametric methods are more efficient and more accurate than non-parametric methods in data usage, a simulation of a large number of observations leads to convergent non-parametric estimates. In our case here, we have simulated 50000 correlated observations by variable and by subsample, and then we performed kernel estimates using the normal distribution density. Our choice for the normal distribution density is consistent with the parametric estimate hypothesis. To take into account the macroeconomic equilibrium, we simulated keeping the structure of correlations between the variables. Indeed, we handled this issue by decomposing the variance-covariance matrix according to Cholesky method in order to generate correlated random observations. The non-parametric estimates figures are exhibited in table 6 below.

Table 6: Nonparametric estimates by sub- sample

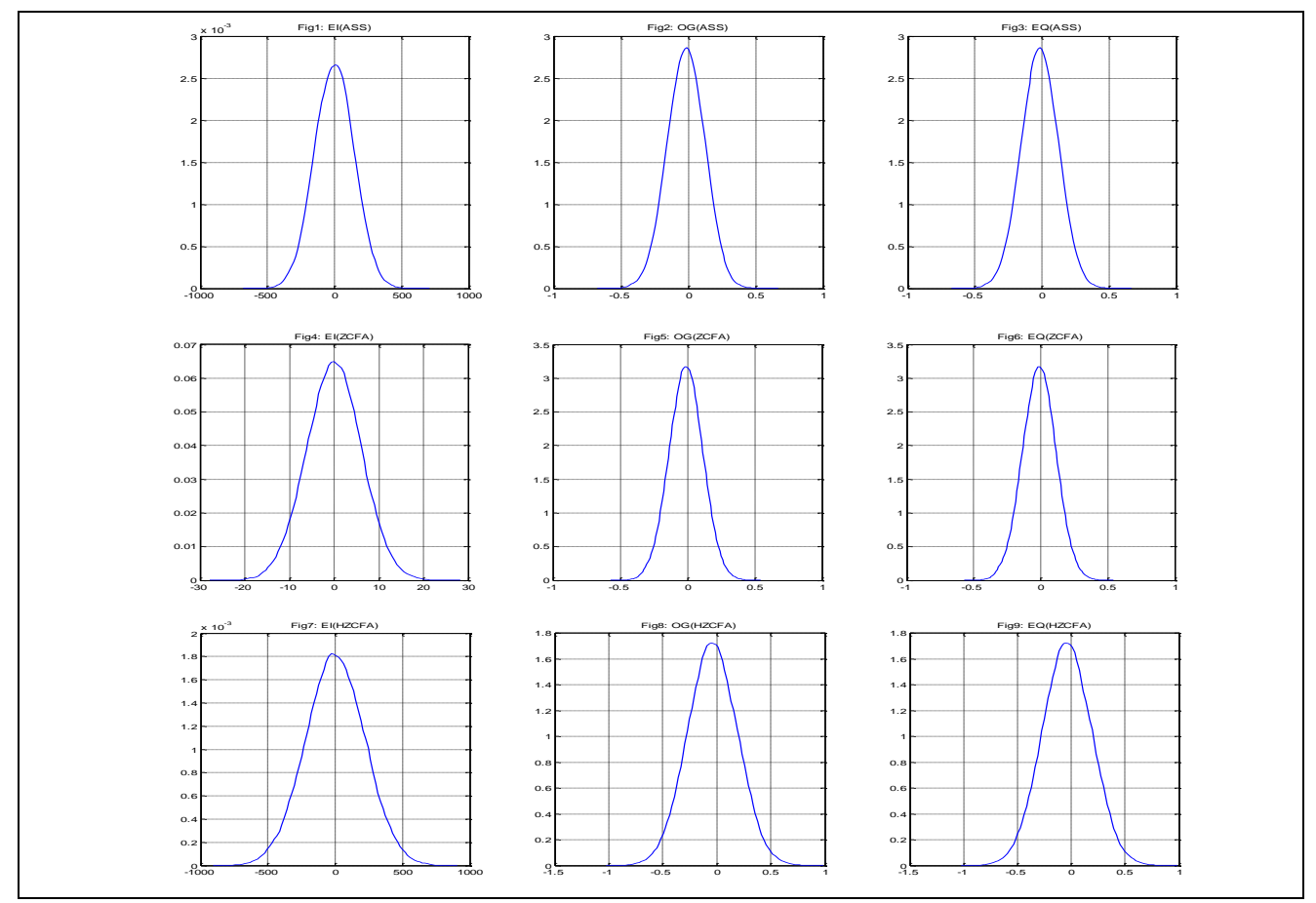



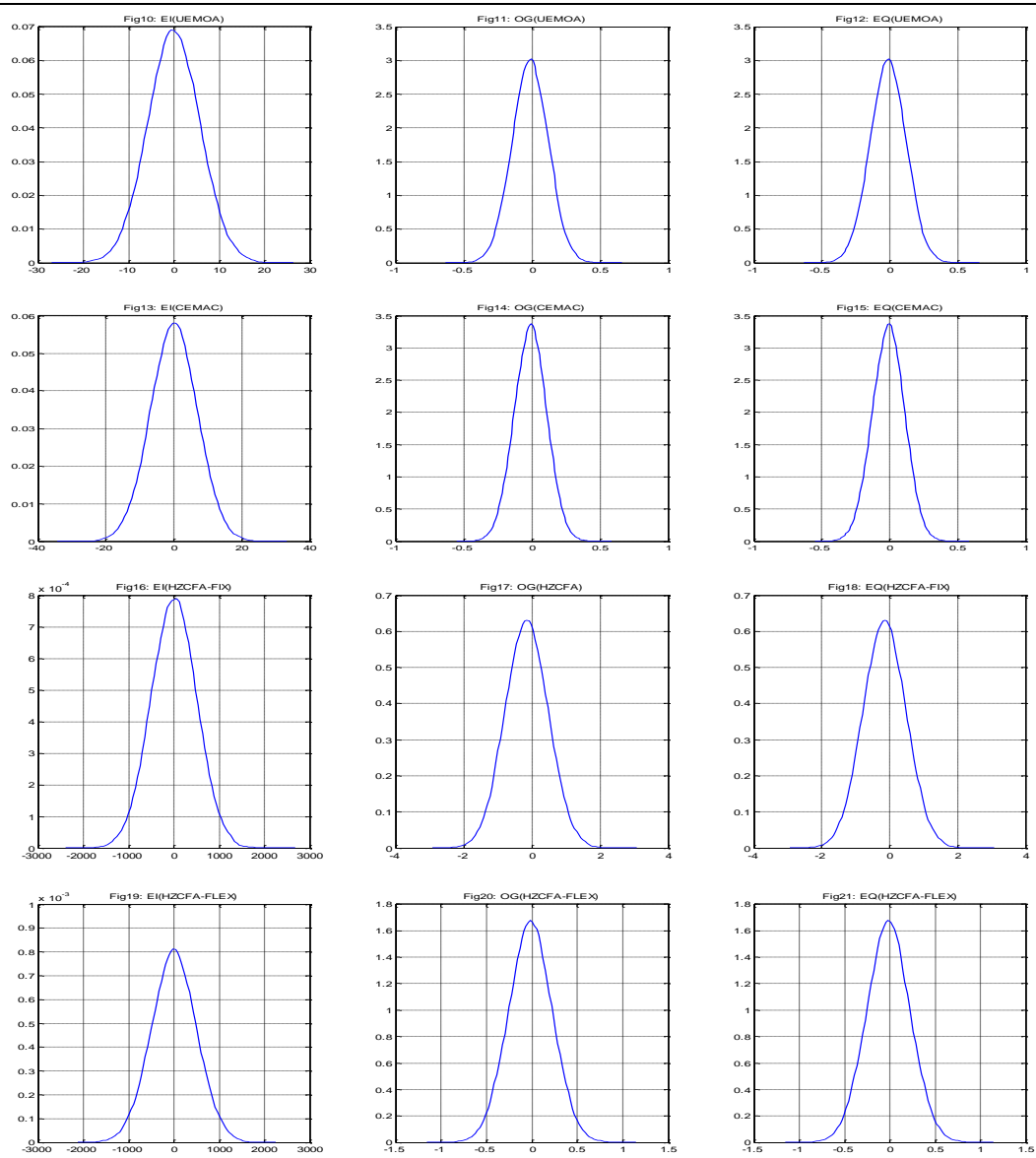

\section{Results and commentary}

As our parametric models failed, then we solely relied on the non-parametric method. According to simulations and estimates' results shown in table 6, it is clearly shown that the macroeconomic instabilities are very high in SSA although the results are different depending on the subsamples. With respect to the global sample, SSA, the distribution of inflation gaps (fig 1 ), is spread out on the range of [-1000, 1000], and the distributions of output gaps (fig. 2) and RER gaps (fig3) are both spread out on the same range of $[-1,1]$. Therefore, it is definitely clear that the instability of inflation is the most important macroeconomic instability in SSA. Regarding to the subsamples, the distributions of inflation gaps are spread out on the intervals of $[-30,30]$ and $[-1000,1000]$ respectively for ZCFA (fig 4) and HZCFA (fig 7). Let point out that there is a very significant difference between the two subsamples the two latter subsamples. Furthermore, the distribution is spread in the range of $[-30,30]$ for the subsample WAEMU (UEMOA: fig 10), and the distribution is spread out on the range of $[-40,40]$ for the subsample CAEMC (CEMAC: fig. 13). 
And with regards to the subsample of countries outside CFA franc zone, HZCFA, the two distributions are spread out on the rage of $[-3000,3000]$ both for the subsample HZCFA with fixed exchange rate regimes or HZCFA-FIX (fig. 16) and the subsample HZCFA with flexible exchange rate regimes or HZCFA-FLEX (fig. 19). On the one hand, the above results reveal that the CAEMU is slightly more instable than the UEMOA (WAEMU) in term of inflation. And on the other hand, the two subsamples of HZCFA are not specifically different in term of inflation. It is relevant to recall that the CAEMC zone is formed by oil exporting countries contrarily to countries in the WAEMU zone. Hence, the CAEMU zone may more frequently face up more with the inflation instability than the WAEMU zone because of high volatility of oil prices undergo on through international market of commodities. Besides, these results reveal that in the case of SSA, the countries with fixed exchange rate regimes are not more performing than those with flexible exchange rate regimes in terms of inflation.

Regarding to the output gaps, the distributions are spread out on the rage of $[-1,1],[-1,1]$ and $[-1.5,1]$ respectively for the global sample (fig. 2), the subsample ZCFA (fig. 5), and the subsample HZCFA (fig. 8). Thus, the ZCFA group has less output gaps instability than the HZCFA group. Indeed, the HZCFA group's range is larger than the ZCFA group's range, and the first group has an asymmetric distribution at the left-hand side, which means that the group often was in the situation where the current output was below the long-run output. In the ZCFA group, the two subsamples have the same distribution, which is spread on the interval of $[-1,1]$ (fig 11 and fig 14). However, for the two groups of HZCFA, the distributions are very different. Indeed, the subsample HZCFA with fixed exchange rate regimes has a distribution spread on the interval of $[-4,4]$ (fig 17), whereas the subsample HZCFA with flexible exchange rate regimes has a distribution spread on the interval of $[-1.5,1.5]$ (fig. 20). The range of the first subsample is more than two times larger than the second one's range. Though the output gaps are very volatile for the two subsamples, this result shows that they are rather extremely volatile for the group with fixed exchange rate regimes.

Finally, regarding to the RER gaps, the distribution of the global sample is spread on the interval of $[-1,1]$ (fig. 3), that of the subsample ZCFA is also spread on the interval of $[-1,1]$ (fig. 6), and that of the subsample HZCFA is spread on the interval of [-1.5, 1.5] (fig 9). Again for this variable also, we note that the instability of the RER is higher for the subsample HZCFA comparatively to the subsample ZCFA as we can obviously see that the former's distribution is asymmetrical on the left-hand side. Then, the two subsamples WAEMU and CAEMC are both distributed on the interval of [-1,1] (fig 12 and fig 15). But regarding to the two subsamples HZCFA-FIX and HZCFA-FLEX, it is shown that the distribution of the former is spread on the interval of [-4, 4] (fig. 18), while that of the latter is spread on the interval of $[-1.5,1.5]$ (fig 21). Therefore, the instability of the RER is also higher for the subsample HZCFA-FIX than that of any other subsample.

\section{Conclusion}

In this article, we have carried out an empirical and comparative study of macroeconomic instabilities according to exchange rate regimes in SSA in order to draw a global vision with regards to macroeconomic policies conducted during the last thirty years in SSA. Relying on internal and external macroeconomic equilibria, we have chosen three variables as macroeconomic instabilities' indicators, which are the inflation gaps, the output gaps and the RER gaps. We first strove to estimate the conditional correlations and 
conditional co-volatilities of variables under consideration using parametric models, especially multivariate GARCH models based on CCC and DCC. But we were obliged to give up this procedure due to technical issue that we could not work out because of lack of observations. Therefore, we were finally forced to rely on semi-parametric and nonparametric methods, especially Monte Carlo simulations and density estimates. These procedures led to the results that demonstrate that macroeconomic instabilities are very high in SSA, and that the results vary depending on exchange rate regimes.

Indeed, we have shown that the macroeconomic instabilities are higher for the countries outside CFA franc zone comparatively to CFA franc zone. Then, the results show that they are higher for the group of countries outside CFA zone with fixed exchange rate regimes than the group of countries outside CFA zone with flexible exchange rate regimes with respect to all studied criteria (instability of inflation, instability of GDP and instability of RER). Contrarily to the standard economic analysis, which assumes that fixed exchange rate regimes are more rigorous in terms of inflation management, we found out that that analysis is not true for the case of SSA countries. The results found out herein may constitute some proofs that many uses of fixed exchange rates in SSA often are related to problems of ineffective economic management. Therefore, political deciders may frequently choose fixed exchange rate regimes in order to alleviate consequences of their economic mismanagement by controlling the price of the local currency and other goods and services. Lastly, we found out that the instability of inflation is associated with those of the output and the RER.

\section{References}

[1] Abdelmalki, L., Gbakou, M. B. P., Sadni-Jallab, M., Sandretto, R. (2012). La stabilité Macroéconomique Conditionne -t- elle l'impact des IDE sur la Croissance Économique et sur le Processus d'Émergence ? Une Étude Empirique sur des Pays d'Afrique, d'Amérique Latine, des Caraïbes et d'Asie.

[2] Acemouglou, D. (2009). Introduction to Modern Economic Growth. New Jersey. Princeton University Press.

[3] Acemouglou, D. et al. (2003). Institutional causes, macroeconomic symptoms: Volatility, crises and growth. Journal of Monetary Economics, 50 (1), 49122.

[4] Aguiar, G., Gopinath, M. (2007). Emerging Market Business Cycles: The Cycle is the Trend. Journal of Political Economy, 115(1), 69-102.

[5] Aizenman, J.,Pinto, B. (2005). Overview. In J.Aizenman, B. Pinto, \& I. H. Pinto (Ed.), Managing Economic Volatility and Crises. Cambridge, United Kingdom: Cambridge University Press.

[6] Agénor, P-R. (2001). Employment Effects of Stabilization Policies. European Journal of Political Economy.

[7] Athanasoulis, S.,Van Wincoop, E. (2000). Growth Uncertainty and Risk Sharing. Journal of Monetary Economics, 45 (3), 477-505.

[8] Baba, Y., Engle, R. F., Kraft, D.,Kroner, K. (1990). Multivariate Simultaneous Generalized ARCH, unpublished manuscript, University of California, San Diego. 
[9] Bauwens, L., Laurent, S., Rombouts, J. V. (2006). Multivariate GARCH Models: A Survey. Journal of Applied Econometrics, 21, 79-109.

[10] Bleaney, M. (1996). Macroeconomic Stability, Investment and Growth in Developing Countries. Journal of Development Economics, 48, 461-477.

[11] Bollerslev, T. (1986). Generalized Autoregressive Conditional Heterokedasticity. Journal of Econometrica, 31, 307-327.

[12] Bollerslev, T. (1990). Modeling the Coherence in Shot-Run Nominal Exchange Rates: A Multivariate generalized ARCH Model. Review of Economics and Statistics, 72, 498-505.

[13] Bollerslev, T., Engel, R. F.,Wooldridge, J. M. (1984). A Captal Asset Pricing Model with Time Varying Covariance. Journal of Political Economy, 96, 116-131.

[14] Dickey, D., Fuller, W. (1981). The Likelihood Ratio Statistics for Autoregressive Time Series with a Unit Root. Econometrica, 49, 1057-1072.

[15] Engle, R. F. (1982). Autoregressive Conditional Heteroscedasticity with Estimates of the Variance of United Kingdom Inflation. Econometrica, 987-1007.

[16] Engle, R. F. (2002). Dynamic Conditional Correlation: A Simple Class of Multivariate Generalized Autoregressive Conditional Heterokedasticity Model. Journal of Business and Economic Statistics, 20, 339-350.

[17] Engle, R. F.,Kroner, F. K. (1995). Multivariate simultaneous generalized ARCH. Econometric Theory, 11, 122-150.

[18] Engle, R. F.,Sheppard, K. (2001). Theoretical and Empirical Properties of Dynamic Conditional correlation Multivariate GARCH. MIMEO, UCSD.

[19] Engle, R. F., Granger, K. (1984). Combining Competing Forecasts of Inflation Using a Bivariate ARCH Model. Journal of Economic Dynamics and Control, 8, 151-165.

[20] Fatàs, A. (2002). The Effects of Business Cycles on Growth. In T. A. Sources, eds Economic Growth, Santiago, Central Bank of Chile of Chile

[21] Guillaumont, P. (2006). Macro Vulnerability in Low-Income Countries and Aid Responses. World Bank Conference on Development Economics - Europe 2006.

[22] Hnatkovska, V., Loayza, N. (2005). Volatility and Growth. In B. P. J. Aizenman, Managing Economic Volatility and Cries. Cambridge, United Kingdom: Cambridge University Press.

[23] Hodrick, R. J., Prescott, E. C. (1997). Post War US Business Cycles: an Empirical Investigation. Journal of Money, Credit and Banking, 29, 1-16.

[24] Phillips, P.,Perron, P. (1988). Testing fo a Unit Root in Time Series Regression. Biometrica , 75, 335-346.

[25] Ramey, G., Ramey, V. (1995). Cross Country Evidence on the Link between Volatility and Growyh. American economic Review, 85 (5), 1138-51.

[26] Sadni-Jallab, M., Gbakou, M. B. P., Sandretto, R. (2008).Foreign Direct Investment, Macroeconomic Instability and Economic Growth. Gate Working Paper.

[27] Sheedy, E. (1998). Correlation Currency Markets: A Risk Adjusted Perspective. Journal of Financial Market, Institution and Money, 8, 59-82. 
[28] Tse, Y. K., Tsui, K. C. (2002). A Multivariate Generalized Orthogonal GARCH Model. Journal of Applied Econometrics, 17, 549-564.

[29] Wolf, H. (2005). Volatility: Definitions and Consequences. In J. A. B. Pinto, Managing Economic Volatility and Crises. Cambridge, United Kingdom. Mass.: Cambridge University Press.

\section{Article history:}

- Received 12 September 2015

- Accepted 28 October 2015 